Bangladesh J. Pl. Breed. Genet., 28(2): 17-24, 2015

\title{
GENOTYPE-ENVIRONMENT INTERACTION IN SPRING WHEAT (Triticum aestivum) OF BANGLADESH
}

\author{
M. S. Islam ${ }^{1}$, T. Halder ${ }^{1}$, J. Hossain ${ }^{2}$, F. Mahmud ${ }^{1}$ and J. Rahman ${ }^{1}$ \\ Department of Genetics and Plant Breeding, Sher-e-Bangla Agricultural University, \\ Sher-e-Bangla Nagar, Dhaka 1207, \\ ${ }^{2}$ Department of Agro-Forestry and Environmental Science, Bangabandhu Sheikh \\ Mujibur Rahman Agricultural University, Gazipur 1706 \\ Corresponding author: gepbtanushree@ sau.edu.bd
}

\begin{abstract}
A field study was conducted to select suitable genotype(s) for varying planting dates and to compare the average performance of the genotypes in different environments. The experiment was conducted at the farm of Sher-e-Bangla Agricultural University, Dhaka, Bangladesh with ten (nine Triticum aestivum and one Triticum turgidum) wheat genotypes. The genotypes were planted at three different dates during November 2012 to March 2013. Analysis of variance for the genotypes showed significant variation which revealed the presence of considerable amount of genetic variability among different genotypes. Significant genotype x environment interaction was obtained for all studied characters and those were tested against pooled error. Environment + (genotype $\wedge^{\wedge}$ environment) component and genotype $\wedge^{\wedge}$ environment (linear) component also showed significant variation and the genotypes performed differently in different environments. Except pooled deviation of linear components of genotype-environment interaction were significant for all the characters. So the differences in stability for different characters were due to the linear response and not for non-linear function. Considering all the characters, genotypes G4, G6, G9 performed better in overall environments. The genotype G10 performed better in poor condition whereas G7 performed better in favorable environment. Among three different sowing dates, optimum sowing (sowing at 20 November, 2012) performed better for most of the genotypes and gradually decreased with late sowing.
\end{abstract}

Key words: Triticum, environment, variability, pooled error, linear response, stability.

DOI: http://dx.doi.org/10.3329/bjpbg.v28i2.29957

\section{INTRODUCTION}

In improving the food security of the world, wheat has played a significant role by contributing about 20 percent of the dietary calories and proteins. On an average $50 \%$ of the wheat in the world is produced in developing regions including Central Asia and China (Shiferaw et al., 2013). Wheat becomes very popular in Bangladesh after the liberation war of Bangladesh in 1971 when it was realized that the country's staple food rice alone was not sufficient to meet the food demand (Hossain et al., 2013). In current agriculture of Bangladesh, wheat occupies the second position next to rice (Anon., 2008). A tremendous change of wheat production and cropping area was seen between $1970-71$ and $1980-81$. The annual mean growth rate was $24.93 \%$. The cropping area rose from 0.126 million ha to 0.591 million ha and production from 0.11 million tons to 1.07 million tons (BARI, 2010). At present about 429.61 thousand hectares of land in our country is covered by wheat with the annual production of $1302998 \mathrm{M}$ tons (BBS, 2014). 
About 1.2 billion to 2.5 billion poor people are "wheat dependent" and "wheatconsuming", respectively and for this reason wheat is called "staff of life" (FAOSTAT, 2010).

Among the wheat species, bread wheat (Triticum aestivum) and durum wheat (T. turgidum) have occupies the third positon in the world crop production (FAO, 2011). From two types of wheat-winter and spring, in Bangladesh only spring wheat is commercially cultivated. Durum wheat is a non-traditional minor ceral in Bangladesh but has commercial importance (BARI, 2015). Wheat still competes with rice, corn and winter vegetables which consider as man cause of lower wheat area (WRC, 2009). The production of wheat is also suffred due to heat stress, drought, declining soil fertility due to climate change (Ortiz et al., 2008). Hence the imporatce of stable crop in various environment arises.

The primary objective of any improvement breeding program is higher yield and improved quality (Khazratkulova et al., 2015). A cultivar's yield will be defined as stable when its yield response of the vareties become consistant across various environments or seasons (Farshadfar et al., 2012). Yield response of genotypes ofentimes fluctuates signficantly due to different environment condtion which is referred as genotype-environment (GE) interaction (Allard, 1964). Hence, to select wide adaptable and stable yielding genotypes GE interaction should be studied (Cecarelli, 1989).

The mean performance appeared to be associated with linear components of genotypeenvironment interaction (Jatasra and Paroda, 1981). Hence, the $\mathrm{G}^{\wedge}{ }^{\wedge} \mathrm{E}$ interaction is an important aspect for both plant breeding programme and introduction of new crop cultivars (McLaren and Chaudhary, 1994). When assessing grain yield of a set of cultivars in a multi-environment trial, changes are in the relative yield performance of cultivars with respect to each other across sites is found. This differential yield response of cultivars from one environment to another is called genotype environment interaction (GEI) and can be studied, described, and interpreted by statistical models (Crossa, 1990). The prime objective of the experiment was to select stable genotype(s) suitable for optimum, late and very late to find out the comparative performance of the genotypes over the different growth period and to identify the suitable genotypes for further wheat breeding programme.

\section{MATERIALS AND METHODS}

The study was conducted at the experimental farm of Sher-e-Bangla Agricultural University (SAU), Sher-e-Bangla Nagar, Dhaka-1207, in three successive sowing dates: 20 Nov, 05 Dec and 20 Dec, 2012, respectively. Three different sowing dates were used as three separate environment and 10 wheat genotypes collected from Bangladesh Agricultural Research Institute (BARI) were used as experimental materials. The details of these genotypes are given in Table 1. The field experiment was set up on the medium high land of the experimental farm. The climate of the experimental site was sub-tropical characterized by heavy rainfall during April to July and sporadic during the rest of the year (BDM, 2012-2013). The experiment was conducted in Randomized Complete Block Design (RCBD) with three replications. The genotypes were randomly distributed within the replication. The same experiment was conducted in three different date of planting. The experiment was established in three planting date viz. 20 Nov, 05 Dec and 20 Dec, 2012 respectively. 100-27-40-20-1 kg ha ${ }^{-1}$ of N-P-K-S-B respectively, and $10 \mathrm{t}$ $\mathrm{ha}^{-1}$ cowdung were applied. Total amount of cowdung, P, K, S, B and one third urea were applied during final land preparation. The rest of the urea was applied in two splits at tillering and panicle initiation stage. Seeds were sown on 20 November 2012 
(Optimum), 05 December 2012 (Late) and 20 December 2012 (Very late), respectively. Irrigations were applied at crown root initiation, booting and grain filling stages. Data were recorded on eight morpho-physiological traits such as the days to heading, days to maturity, plant height $(\mathrm{cm})$, spikes $\mathrm{m}^{-2}$, grain spike ${ }^{-1}, 1000$ grain weight $(\mathrm{g})$, biomass $(\mathrm{t}$ $\left.\mathrm{ha}^{-1}\right)$, grain yield $\left(\mathrm{t} \mathrm{ha}{ }^{-1}\right)$.

During data analysis, different sowing dates are considered as separate environment. Data were subjected to analyze by th statistical approches provided by Eberhart and Russell (1966) and Panwar et al. (1995) for the estimation of genotype ${ }^{\wedge}$ environment interaction. The individual genotypic response i.e. regression coefficient (bi) was tested by t- test using the standard error of the corresponding bi value against the hypothesis. The individual deviations from linear regression tested by F-test using pooled error.

Table 1. List of ten wheat genotypes along with their pedigree

\begin{tabular}{c|c|c}
\hline Symbol & Genotypes & Pedigree \\
\hline G1 & KANCHAN ( BAW 28) & UP301/C306 \\
G2 & SOURAV (BARI GOM & 1187-1-1P-5P-5JO-0JO \\
& Nac/Vee \\
G3 & GOURAB (BARI GOM & CM64224-5Y-1M-1Y-2M-0Y \\
& 20) & Turaco/Chil \\
G4 & SHATABDI (BARI & CM92354 33M-oY-0M-6Y-OB \\
& GOM 21) & Mrng/Buc/Blo/Pvn/3/Pjb81 \\
G5 & SUFI ( BARI GOM 22) & Kan/6/Coq/T61.70/Cndr/3/Oln/Pho/5/Mrng/Aldan/Cno \\
& & BD(JE) 349-X-OJE-9DI-10HR \\
G6 & BIJOY (BARI GOM 23) & NL297×2/Lr25 \\
G7 & PRODIP (BARI GOM & G.162/BL1316/NL297 \\
& 24) & \\
G8 & TISTA (BARI GOM 25) & ZSH 12/HLB 19//2*NL297 \\
G9 & HASHI (BARI GOM 26) & ICTAL123/3/RAWAL87//VEE/HD2285 \\
G10 & DURUM & Triticum turgidum L. \\
\hline
\end{tabular}

Source: (The World Wheat Book, 2011).

\section{RESULTS AND DISCUSSION \\ Combined genotypic analysis}

To fulfill the objective of a breeder to get maximum yield of a crop, knowledge of significant genotype-environment interaction is essential. It estimates the parameters of stability of a genotype which is helpful to select the superior stable genotypes across a wide range of environments (Eberhart and Russell, 1966). Combined Analysis of Variance has a great importance to select such genotypes. The results of combined analysis of variance for eight characters of ten wheat genotypes at different environments are presented in Table 2.

Highly significant MS for both genotypes and environments revealed the presence of genetic variability where highly significant MS due to environments (linear) indicated the difference between the environments. Highly significant mean squares due to environments (linear) indicated the difference between the environments. Significant genotypes $\mathrm{x}$ environment interactions were observed when tested against pooled error. Environment + (genotype $\mathrm{x}$ environment) component and genotype $\wedge$ environment (linear) component also showed significant variation and the genotypes performed differently in different environments. Except pooled deviation linear components of genotype- environment interaction were significant for all the characters (Table 2). 
Table 2. Combined ANOVA for eight characters in wheat under three different environments

\begin{tabular}{|c|c|c|c|c|c|c|c|c|c|}
\hline \multirow[b]{2}{*}{ Source of variation } & \multirow{2}{*}{ df } & \multicolumn{8}{|c|}{ Mean sum of squares } \\
\hline & & $\begin{array}{l}\text { Days to } \\
\text { heading }\end{array}$ & $\begin{array}{l}\text { Days to } \\
\text { maturity }\end{array}$ & $\begin{array}{c}\text { Plant } \\
\text { Height }(\mathrm{cm})\end{array}$ & $\begin{array}{c}\text { No. of } \\
\text { Spikes } \mathrm{m}^{-2}\end{array}$ & $\begin{array}{c}\text { No. of Grains } \\
\text { spike }^{-1}\end{array}$ & $\begin{array}{l}1000 \text { Grain } \\
\text { weight }(\mathrm{g})\end{array}$ & $\begin{array}{l}\text { Biomass } \\
\left(\mathrm{t} \mathrm{ha}^{-1}\right)\end{array}$ & $\begin{array}{c}\text { Grain yield } \\
\left(\mathrm{t} \mathrm{ha}^{-1}\right)\end{array}$ \\
\hline Genotype & 9 & $51.04 * *$ & $40.97 * *$ & $49.73 * *$ & $1092.20 * *$ & $2.00 * *$ & $57.20 * *$ & $0.45^{* *}$ & $0.13 * *$ \\
\hline Environment & 2 & $51.76^{* *}$ & $279.95 * *$ & $146.78 * *$ & $920.26^{* *}$ & $27.40 * *$ & $74.02 * *$ & $8.80 * *$ & $2.23 * *$ \\
\hline Gen.× Env. & 18 & $2.10 *$ & $2.23 *$ & $2.64 *$ & $96.23 * *$ & $0.70 *$ & $1.72 *$ & $0.19 *$ & $0.05 *$ \\
\hline Env.+(Gen.× Env.) & 20 & $7.07 * *$ & $30.00 * *$ & $17.06 * *$ & $178.63 * *$ & $3.37 * *$ & $8.95^{* *}$ & $1.05^{* *}$ & $0.27 * *$ \\
\hline Env. (Linear) & 1 & $103.52 * *$ & $559.90 * *$ & $293.56^{* *}$ & $1840.52 * *$ & $54.80 * *$ & $148.04 * *$ & $17.60 * *$ & $4.46^{* *}$ \\
\hline Gen. $\times$ Env. (Lin) & 9 & $4.01 * *$ & $4.07 * *$ & $2.95 * *$ & $162.78 * *$ & $0.99 * *$ & $2.69 * *$ & $0.30 * *$ & $0.09 * *$ \\
\hline Pooled Deviation & 10 & 0.18 & 0.35 & 2.10 & 26.71 & 0.37 & 0.67 & 0.06 & 0.01 \\
\hline $\mathrm{G} 1$ & 1 & 0.04 & 0.28 & 0.37 & 13.12 & 0.34 & 0.12 & 0.01 & 0.01 \\
\hline $\mathrm{G} 2$ & 1 & 0.18 & 0.28 & 0.01 & $134.71 * *$ & 0.80 & $0.72 *$ & $0.06^{* *}$ & 0.03 \\
\hline G3 & 1 & 0.72 & 0.37 & 0.17 & 0.58 & 0.00 & 0.20 & $0.04 * *$ & 0.01 \\
\hline G4 & 1 & 0.16 & 0.45 & 2.36 & 16.07 & 0.17 & $4.38 * *$ & $0.16^{* *}$ & 0.01 \\
\hline G5 & 1 & 0.22 & 0.16 & $11.03 * *$ & 14.41 & 0.08 & 0.14 & $0.07 * *$ & 0.00 \\
\hline G6 & 1 & 0.00 & 0.51 & $5.21 *$ & 17.11 & 1.05 & 0.37 & $0.15^{* *}$ & 0.00 \\
\hline G7 & 1 & 0.03 & 0.23 & 0.09 & 8.25 & 0.38 & 0.13 & 0.00 & 0.03 \\
\hline G8 & 1 & 0.16 & 0.84 & 1.35 & 22.98 & 0.04 & 0.02 & $0.04 * *$ & 0.00 \\
\hline G9 & 1 & 0.24 & 0.24 & 0.26 & 15.63 & 0.83 & 0.45 & 0.01 & 0.01 \\
\hline G10 & 1 & 0.00 & 0.19 & 0.11 & 24.24 & 0.05 & 0.20 & $0.06^{* *}$ & 0.00 \\
\hline Pooled Error & 54 & 0.50 & 0.63 & 1.27 & 7.08 & 0.46 & 0.50 & 0.01 & 0.01 \\
\hline
\end{tabular}


So the differences in stability for different characters were due to the linear response and not for non-linear function. The significant $\mathrm{E}+(\mathrm{G} \times \mathrm{E})$ component indicated variable response of the genotypes to different environments. Amin et al. (2005) also found that there was genetic and environmental variability among the genotypes due to variance in pooled analysis of variance.

The regression coefficient (bi) value close to zero indicates the better performance of genotypes in the for the poor environment and when the value is significantly more than unity means the genotypes are better for the favorable environments. When a genotype shows higher mean value for a character, higher phenotypic index (Pi) with one unit bi and $S^{2}$ di approaching to zero, then the genotype will be stable for the character (Eberhart, 1966). Higher environmental index (Ij) is the indication of favorable environment for a distinct character that needs to increase to improve the yield and viceversa.

Maximum and minimum days to heading were found in G5 and G10, respectively. The genotypes G2, G3, G5, G7, G8, G9 were not stable to environmental changes due to greater difference of bi from unit (Table 3). $E_{2}$ and $E_{3}$ were favourable for the character. The genotype G7 can be considered best for poor environment when G1 and G6 could be considered stable for early heading due to the highest negative Pi value, insignificant bi and $S^{2}$ di value (Figure1). The genotypes, G10, G9 and G8 showed positive phenotypic indices with bi value more than one thus desirable for late heading and fluctuate with environmental variation. Mahal et al. (1988) also reported variable linear response for days to heading in wheat.

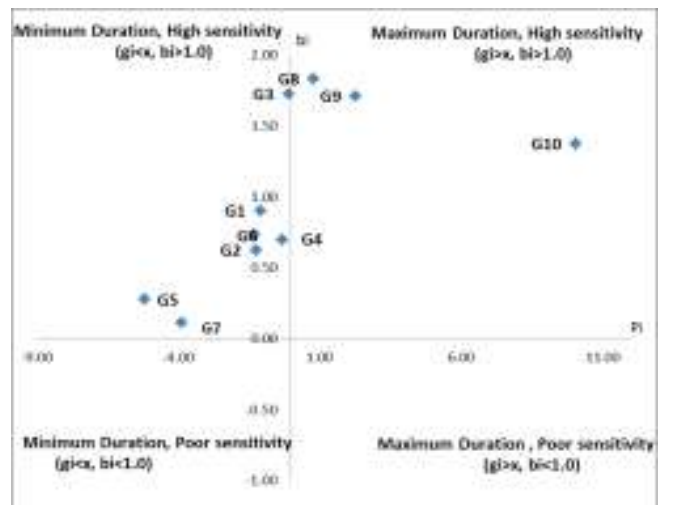

Figure 1. Adaptive specificities of ten wheat genotypes for days to heading

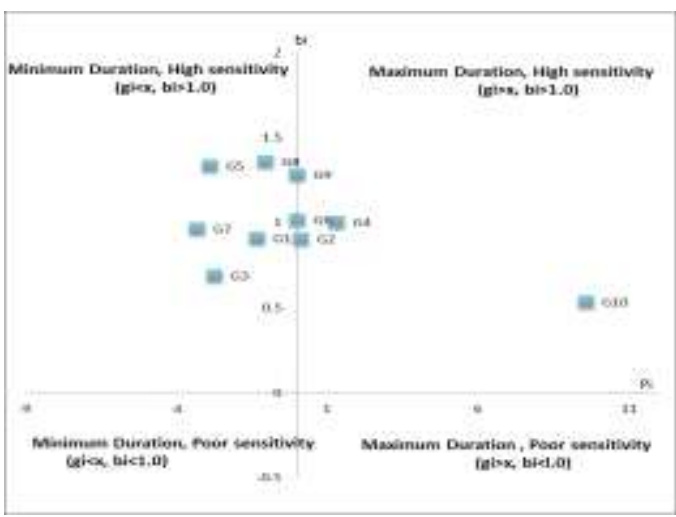

Figure 2. Adaptive specificities of ten wheat genotypes for days to maturity

Maximum and minimum days to maturity were found in G7 and G10, respectively. The geotypes G3, G5, G8, G9 and G10 showed significant bi value indicating that these genotypes were not stable to environmental changes. The result was supproted by Barma et al. (1994) who also found different genotypes with non-significant deviation from regression and very little environmental sensitivity for days to maturity. Genotypes G2, G4, G6, G9 and G10 were desirable for late maturity and the G1, G3, G5, G7 and G8 for early maturty due to positive and negative $\mathrm{Pi}$, respectively. The highest negative $\mathrm{Pi}$ value, insignificant bi and $S^{2}$ di value found for the genotypes, G1 and G7 which could be considered better for early maturity with stable performance. The genotype G4 can be recommended for stable genotype for days to maturity as the bi was was exactly 1.0 (Figure 2). 
Among the genotypes, G6 and G10 showed maximum and minimum height respectively. None of the genotpes showed significant bi value that indicated no environmental sensitivity for plant height. No linear prediction was possible for G5 and G6 genotype for their $S^{2}$ di value. In Figure 3, genotypes, G2, G3, G5, G9 and G10 showed negative Pi value and insignificant bi value and could be considered better for plant height with stable performance.

Significant bi value different from unity indicates the instability of G2, G4, G7 genotypes with environment. Among the genotypes, G9 and G10 showed maximum and minimum spikes $\mathrm{m}^{-2}$ respectively. $\mathrm{E}_{1}$ was the most favorable envrironment for more spikes $\mathrm{m}^{-2}$ as the $\mathrm{I}_{\mathrm{j}}$ was highest in the case. According to the stability condition, G6 and G9 could be considered stable genotype for the trait (Figure 4). Although G4 showed higher Pi value, it would not stable to the varying environment due to its higher significant bi value but could be recommended for the favorable environments.

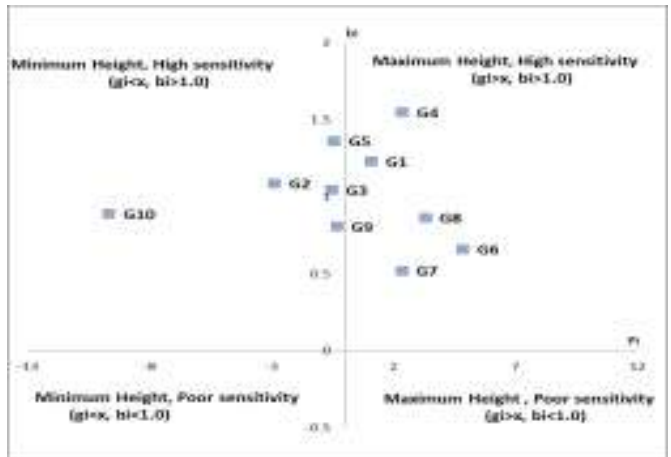

Figure 3. Adaptive specificities of ten wheat genotypes for plant height.

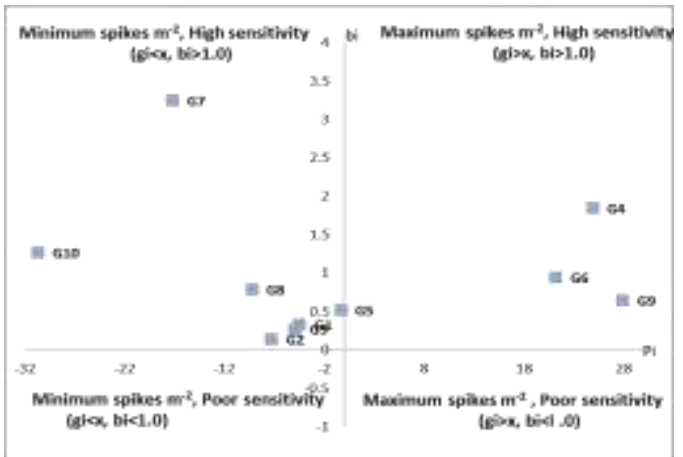

Figure 4. Adaptive specificities of ten wheat genotypes for spike $\mathrm{m}^{-2}$.

It was revealed that the genotype G5 and G1 showed maximum and minimum grains spike $^{-1}$, respectively. Due to significant regression coefficient value which was different from unity, it could be told that G7 will be sensitive to environemtnal change. Haque et al. (2003) also found a range of stability based on bi value for grains spike ${ }^{-1}$. $E_{1}$ could be considered as favorable environment due to positive $\mathrm{I}_{\mathrm{j}}$. G3 and G5 can be considered as stable variety for the trait due to positive Pi value, insignificant bi and $S^{2}$ di value (Fig 5).

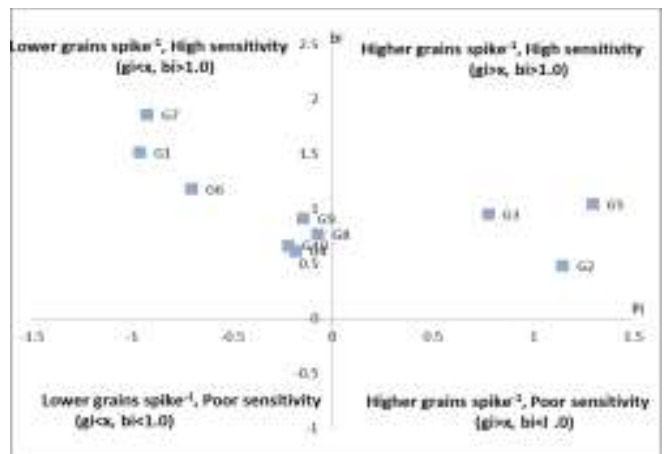

Figure 5. Adaptive specificities of ten wheat genotypes for grains spike ${ }^{-1}$.

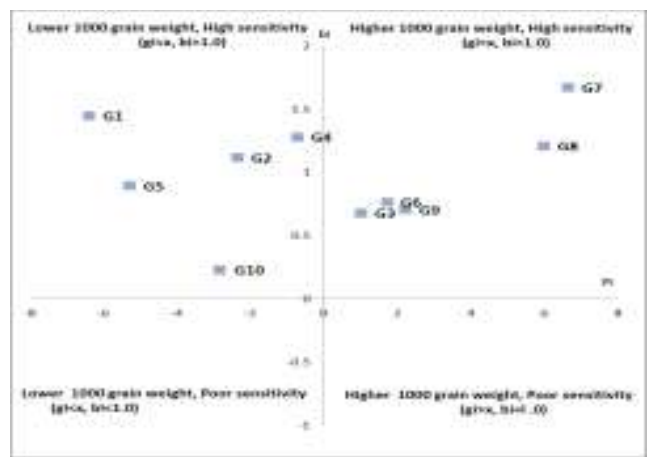

Figure 6. Adaptive specificities of ten wheat genotypes for 1000 grain wt (g).

Genotypes, G7 and G1 showed maximum and minimum 1000 grain weight, respectively. Significant bi value of G1, G7, G10 genotypes indicated their instability to 
environmental change. No linear prediction was possible for G4 due to significant $\mathrm{S}^{2} \mathrm{di}$. Aycieck and Yildirim (2006) found that there was significant difference among the genotypes for 1000 grain weight. $E_{1}$ was considered favorable due to positive $I_{j}$. The genotype G8 would consider more stable genotype for the trait than G3, G6 and G9 due to insignificant bi near to unity, positive $\mathrm{Pi}$ and lower $\mathrm{S}^{2}$ di value (Figure 6). Maximum and minimum value of biomass was found in G4 and G5 genotype, respectively. Sensitivity to environmental change was found in G6, G7, G10 genotypes showed significant regression coefficient value (Table 6). Linear prediction was impossible for G2, G3, G4, G5, G6, G8, G10 showed deviation from regression coefficient different from zero. $E_{1}$ would consider best envirnment for biomass due to positive $I_{j}$. G2, G5, G7 and G10 showed negative Pi indicating lower biomass yield (Figure 7). Genotype, G1 and G9 could be considered for higher biomass yield with stable performance due to highest positive $\mathrm{Pi}$ value, insignificant bi and $\mathrm{S}^{2}$ di value. Hamam et al. (2009) also reported that there were differences in stability performances for biomass among the genotypes.

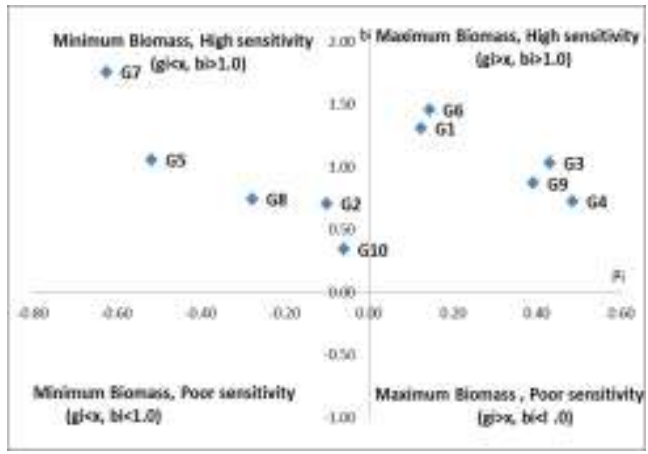

Figure 7. Adaptive specificities of ten wheat genotypes for biomass $\left(\mathrm{t} \mathrm{h}^{-1}\right)$.

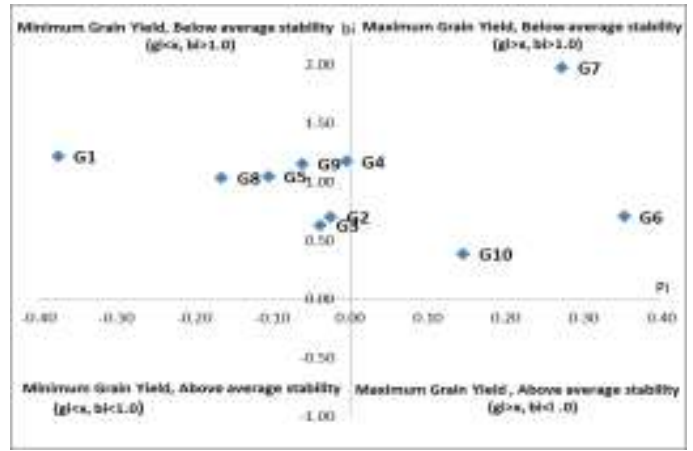

Figure 8. Adaptive specificities of ten wheat genotypes for grain yield $\left(\mathrm{t} \mathrm{ha}^{-1}\right)$.

It was found that G6 and $\mathrm{G} 1$ produced maximum and minimum grain yield $\left(\mathrm{t} \mathrm{ha}^{-1}\right)$, respectively. As the bi was significant for G3, G7 and G10, they became sensitive to environmental alteration. Linear predicaiton was possible for all genotypes as none of them showed significant $S^{2} d_{i}$ value. Islam et al. (1981) also found some high yielding genotypes to be sensitive to environmental changes due to their relatively higher regression coefficient. Amen et al. (2005), Grausgruber et al. (2000) and Peterson et al.(1998) found that the grain yield of wheat was influenced by GE interaction. From the value of environmental index it could be tell that the $E_{1}$ was more favorable and $E_{2}$ was moderately favorable for higher grain yield. The genotypes G4, G6 and G9 could be considered as stable genotypes for grain yield due to positive $\mathrm{Pi}$, insignificant bi and insignificant $S^{2}$ di value (Figure 8).

\section{REFERENCES}

Allard R.W. and A. D. Bradshaw . 1964. Implication of genotype-environmental interaction in applied plant breeding. Crop Science. 5: 503-506.

Amin, M. R., A. Islam, A. Shaheed, and N. C. D. Barma. 1993. Stability of yield and its components in wheat. Bangladesh J. Agril. Sci. 20(2): 203-211.

Amin, M., T. Mohammad, A. J. Khan, M. Irfaq, A. Ali and G. R. Tahir. 2005. Yield stability of spring wheat (Triticum aestivum L.) in the North West Frontier Province, Pakistan. Songklanakarin J. Sci. Technol. 27(6): 1147-1150.

Anonymous. 2008. Statistical year book of Bangladesh.2006. Bangladesh Bureau of Statistics. Ministry of Planning. Government of the People's Republic of Bangladesh. 
Aycicek, M. and T. Yildirim. 2006. Adaptability performances of some bread wheat (Triticum aestivum L.) genotypes in the Eastern region of Turkey. Inter. J. Sci. Tech. 1(2): 83-89.

BARI (Bangladesh Agricultural Research Institute). 2010. Wheat production in Bangladesh: a success story.http://www.bari.gov.bd/index.php?option=com_simplestforum\&view=postlist\&topic= true\&forumId=1\&parentId=288 (4 November 2012).

BARI. 2015. Bangladesh Agricultural Research Institute , Joydebpur, Dhaka. Annual Report (20142015). p. 7.

BBS. 2014. Bangladesh Bureau of Statistics. Estimates of wheat, 201302014. Government of the Peoples Republic of Bangladesh. Agriculture Wing. Dhaka. p. 1-2.

Barma, N. C. D., A. B. Siddique, Z. I. Sarker, M. A. Samad, and M. A. Razzaque. 1994. Genotype and environment interaction and stability analysis in Wheat. Bangladesh J. Pl. Breed. Genet. 7(1): 31-35.

BMD. 2013. Bangladesh Meteorological Department (Climate \& weather division), Agargoan, Dhaka. Monthly record of air temperature, relative humidity and rainfall of the experimental site during the period from November 2012 to March 2013.

Cecarelli, S. 1989. Wide adaptation. How wide?. Euphytica. 40(3):197-205.

Crossa, J. 1990. Statistical analyses of multilocation trials. Adv. Agron. 44: 55-8.

Eberhart, S. A. and W. A. Russell. 1966. Stability parameters for comparing the varieties. Crop Sci. 6:36-40.

FAOSTAT. 2010. Food and Agricultural com-modities production, Rome, Italy. http://faostat.fao.org.

FAO. 2011. FAOSTAT online database.http://faostat.fao.org/. Accessed on December 2011.

Farshadfar, E., R. Mohammadi, M. Aghaee and Z. Vaisi. 2012. GGE biplot analysis of genotype x environment interaction in wheat-barley disomic addition lines. Australian J. Crop Sci. 2012;6(6):1074-1079.

Grausgruber, H., M. Oberforster, M. Werteker, J. Ruckenbauer, and J. Vollmann, 2000. Stability of quality traits in Austrian-grown winter wheats. Field Crops Res. 66: 257-267.

Hamam, K. A., A. Sabour and G.A. Khaled. 2009. Stability of wheat genotypes under different environments and their evaluation under sowing dates and nitrogen fertilizer levels. Australian J. Basic Appl. Sci. 3(1): 206-217.

Haque, E., G. Kabir, M. A. A. Mondal and A. M. S. Islam. 2003. Bangladesh J. PI. Breed. Genet. 16(1): 39-44.

Hossain, A. and J. A. Teixeira da Silva. 2013. Wheat production in Bangladesh:its future in the light of global warming. AoB Plants 5: pls042; doi:10.1093/aobpla/pls042.

Islam. R., O. I. Joarder and A. M. Eunus. 1981. Genotypes x seeding date interaction in wheat. Bangladesh J. Bot. 10(2): 195-200.

Jatasra, D. S. and R.S. Paroda.1981. Genotype-environment interaction in segregating generation of wheat. Indian J. Genet. 41: 12-17.

Kharatukulova S., R. C. Sharma, A. Amanov, Z. Ziyadullaev, O. Amanov, S. Alikulov, Z. Ziyaev and D. Muzararova. 2015. Genotype $\times$ environment interaction and stability of grain yield andselected quality traits in winter wheat in Central Asia. Turk J. Agric. For. 39:920-929.

Mahal. K. S., S. Gill and G. S. Bhullar. 1988. Stability parameters and performance of different crosses in durum wheat (Triticum durum). Theo. Appl. Genet. 76(3): 438-442.

McLaren, C. G. and R. C. Chaudhary. 1994. Use of additive main effects and multiplicative interaction models to analyse multilocation rice variety trials. Paper presented at the 1994 FCSSP Conference, Princesa, Palawan. Philippines.

Ortiz, R., K. D. Sayre, B. Govaerts, R. Gupta, G. V. Subbarao and T. Ban. 2008. Climate change: can wheat beat the heat? Agriculture, Ecosystems \& Environment, 126, 46-58.

Panwar, K. S., H. K. Chaudhary and S. R. Thakur. 1995. Stability in seed yields of french bean (Phaseolus vulgaris) genotypes in high hill dry temperate regions of north western Himalayas. Indian J. Agril. Sci. 65(5): 341-44.

Peterson, C. J., R. A. Graybosch, D. R. Shelton and P. S. Baenziger. 1998. Baking quality of winter wheat: response of cultivars to environment in the Great Plains. Euphytica. 100: 157-162.

Shiferaw, B., S. Melinda, B. Hans-Joachim , D. Etienne, R. Mathew and M. Geoffrey. 2013. Crops that feed the world 10. Past successes and future challenges to the role played by wheat in global food security. Food Sec. 5: 291-317.

WWB (World Wheat Book). 2011. A History of Wheat Breeding. Volume 2. Lavoisier Publisihing. France. 363.

WRC (Wheat Research Centre). Annual Report, 2008-09. 2009; 181. 